\title{
Genistein induces adipogenic differentiation in human bone marrow mesenchymal stem cells and suppresses their osteogenic potential by upregulating PPAR $\gamma$
}

\author{
LI-YAN ZHANG ${ }^{1,2}$, HAO-GANG XUE ${ }^{2}$, JI-YING CHEN $^{1}$, WEI CHAI $^{1}$ and MING NI ${ }^{1}$ \\ ${ }^{1}$ Department of Orthopedics, General Hospital of Chinese People's Liberation Army, Beijing 100853; \\ ${ }^{2}$ First Department of Orthopedics, The Affiliated Hospital of Beihua University, Jilin, Jilin 132001, P.R. China
}

Received May 15, 2015; Accepted January 11, 2016

DOI: $10.3892 /$ etm.2016.3120

\begin{abstract}
Genistein is a soy isoflavone that exists in the form of an aglycone. It is the primary active component in soy isoflavone and has a number of biological activities (anti-inflammatory and anti-oxidative). However, the specific effect of genistein on human bone marrow mesenchymal stem cells (BMSCs) remains unclear. In the present study, the mechanism underlying the effect of genistein on the suppression of BMSC adipogenic differentiation and the enhancement of osteogenic potential was investigated using an MTT assay. It was observed that genistein significantly increased BMSC cell proliferation in a time- and dose-dependent manner $(\mathrm{P}<0.01)$. In addition, reverse transcription-quantitative polymerase chain reaction revealed that genistein significantly inhibited the expression of runt-related transcription factor 2 (Runx2), type I collagen (Col I) and osteocalcin (OC; $\mathrm{P}<0.01)$. Furthermore, $20 \mu \mathrm{m}$ genistein significantly inhibited the activity of alkaline phosphatase (ALP) and increased the activity of triglycerides (TGs) increased $(\mathrm{P}<0.01)$ as determined by an enzyme-linked immunosorbent assay. Finally, western blotting revealed that BMSC pretreatment with $20 \mu \mathrm{m}$ genistein significantly increased peroxisome proliferator-activated receptor $\gamma(\operatorname{PPAR} \gamma)$ protein expression $(\mathrm{P}<0.01)$. This suggests that the downregulation of PPAR $\gamma$ may significantly reduce the effect of genistein on cell proliferation, suppress the expression of Runx2, Col I and OC mRNA, and reduce ALP and promote TG activity in BMSCs. Thus, the results of the present study conclude that genistein induces adipogenic differentiation in human BMSCs and suppresses their osteogenic potential by upregulating the expression of
\end{abstract}

Correspondence to: Dr Ji-Ying Chen or Dr Wei Chai, Department of Orthopedics, General Hospital of Chinese People's Liberation Army, 28 Fuxing Road, Haidian, Beijing 100853, P.R. China

E-mail: chenjiying_301@yeah.net

E-mail: 5170765@qq.com

Key words: genistein, bone marrow mesenchymal stem cells, adipogenic, osteogenic, peroxisome proliferator-activated receptor- $\gamma$
PPAR $\gamma$. In conclusion, genistein may be a promising candidate drug for treatment against osteogenesis.

\section{Introduction}

Bone marrow mesenchymal stem cells (BMSCs) are fibrocyte-like stem cells that exist alongside hematopoietic stem cells within the marrow cavity. BMSCs are highly self-renewable with multipotential differentiation (1); they may develop into osteoblasts, chondrocytes and adipose cells through directional differentiation, and at present it is understood that all osteoblasts are derived from BMSCs (2).

Peroxisome proliferator-activated receptor $\gamma(\operatorname{PPAR} \gamma)$ is a PPAR subtype that contributes towards the regulation of cell differentiation, proliferation and apoptosis $(3,4)$. To date, it is understood that the PPAR $\gamma$ subtype is the primary regulator of fat differentiation, which serves a key regulatory role in the direction of BMSC differentiation (5). In the marrow cavity, osteoblasts and adipocytes are derived from BMSCs, and it is understood that there is an association between their expression levels (6). Previous studies demonstrate that PPAR $\gamma$-mediated adipogenic differentiation of BMSCs directly affects the differentiation of osteoblasts $(7,8)$. Osteoclasts are derived from hematopoietic stem cells in bone marrow, and are responsible for increased bone resorption and osteoporosis; this is demonstrated through an increase of fat in bone marrow cavities that occurs in every type of osteoporosis $(9,10)$.

Soy isoflavone is a class 1 secondary metabolite that is formed during the growth of soybeans. In total, 12 types of natural isoflavones exist in soybeans, including daidzin, daidzein, genistin, genistein, glycitin and glycitein (11). Of these, genistein possesses the highest level of activity (12). Genistein possesses a number of bioactivities (13); it is an effective antioxidant, a protein tyrosine activating enzyme inhibitor and a phytoestrogen (14). In recent years, increasing evidence indicates that genistein may aid in the prevention and treatment of breast cancer, prostatic cancer, post-menopause syndrome, osteoporosis and angiocardiopathy $(15,16)$. In the present study, the mechanisms underlying the effect of genistein on the suppression of human BMSC adipogenic differentiation 
and the enhancement of BMSC osteogenic potential were investigated.

\section{Materials and methods}

Reagents. Dulbecco's modified Eagle's medium (DMEM) and fetal bovine serum (FBS) were provided by Gibco (Thermo Fisher Scientific, Inc., Waltham, MA, USA), and genistein (Fig. 1; $\geq 98 \%$, high-performance liquid chromatography) and 3-(4,5-dimethylthiazol-2-yl)-2,5-diphenyltetrazolium bromide (MTT) were provided by Sigma-Aldrich (St. Louis, MO, USA).

BMSC culture and identification. The use of animals in the present study was approved by the Animal Care and Use Committee of the Chinese People's Liberation Army General Hospital (Beijing, China). A total of 20 male and female Sprague-Dawley rats (age, 2-4 weeks; $100 \pm 10$ g; male $=24$, female $=24$; purchased from Charles River Laboratories, Wilmington, MA, USA) were used to isolate marrow-derived BMSCs and were housed in an animal quarter (humidity, 60-70\%; temperature, $23 \pm 1^{\circ} \mathrm{C}$; 12 -h light-dark cycle) with ad libitum access to food and water. Rats were sacrificed by cervical dislocation and BMSCs were isolated according to a previously described method (17). Briefly, bone marrow was flushed from the femur and tibia with saline, and placed into $25 \mathrm{~cm}^{2}$ flasks with DMEM supplemented with $10 \% \mathrm{FBS}$, 100 units penicillin and $100 \mu \mathrm{g}-\mathrm{ml}$ streptomycin (both purchased from Sigma-Aldrich), and was incubated at $37^{\circ} \mathrm{C}$ in a humidified atmosphere containing $5 \% \mathrm{CO}_{2}$ for 1 day. Following the incubation period, nonadherent cells were removed and adherent cells were washed with phosphate-buffered saline (PBS; Sinopharm Chemical Reagent Co., Ltd., Shanghai, China). Next, adherent cells were incubated with DMEM for $2 \mathrm{~h}$ at $37^{\circ} \mathrm{C}$ and washed with PBS once they reached $80-90 \%$ confluence. The cells were detached using 0.25\% trypsin (Nanjing Sunshine Biotechnology, Co., Ltd., Nanjing, China) and the remaining cells were incubated in new $25 \mathrm{~cm}^{2}$ flasks.

BMSCs were treated with genistein $(0,5,10$ and $20 \mu \mathrm{m})$ for 1, 2 or 3 days or GW9662 (1 mM; Invitrogen; Thermo Fisher Scientific, Inc.), a PPAR $\gamma$ inhibitor. BMSCs were then fixed using 5\% pre-cooled paraformaldehyde (Sinopharm Chemical Reagent Co., Ltd.) for $10-15 \mathrm{~min}$ at $4^{\circ} \mathrm{C}$, and cultured with hematoxylin and eosin staining (Invitrogen; Thermo Fisher Scientific, Inc.) for $10 \mathrm{~min}$. Next, BMSCs were washed using tap and distilled water for 5-10 min. Stained BMSCs were dehydrated with $95 \%$ ethanol for 1-2 min and xylene (Shangbeijia Biological Technology Co., Ltd.) was applied for 5-10 min until transparent. BMSCs were analyzed using a microscope (TE2000; Nikon Corporation, Tokyo, Japan).

Grouping and cell proliferation assay. BMSCs were seeded in 96-well plates and incubated with different concentrations of genistein $(0,5,10$ and $20 \mu \mathrm{m})$ for 1, 2 and 3 days or GW9662 $(1 \mathrm{mM})$. In the MTT cell proliferation assay, BMSCs were incubated with $20 \mu \mathrm{l} \mathrm{MTT}$ for $4 \mathrm{~h}$ at $37^{\circ} \mathrm{C}$ in a humidified atmosphere containing $5 \% \mathrm{CO}_{2}$. Once the medium was removed, $150 \mu \mathrm{l}$ dimethyl sulfoxide was added for $10 \mathrm{~min}$ at room temperature. The optical density was read at $570 \mathrm{~nm}$ (Epoch Microplate Spectrophotometer; BioTek Instruments, Inc., Winooski, VT, USA).

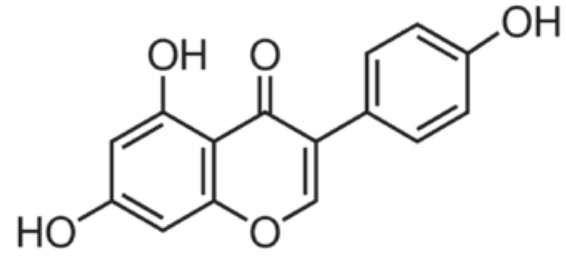

Figure 1. Chemical structure of genistein.

Reverse transcription-quantitative polymerase chain reaction (RT-qPCR) of runt-related transcription factor 2 (Runx2), collagen type I (Col I) and osteocalcin (OC). Following treatment with genistein, total RNA $(1 \mu \mathrm{g})$ was extracted using TRIzol reagent (Invitrogen; Thermo Fisher Scientific, Inc.) and BMSC cDNA $(1 \mu \mathrm{g})$ was transcribed using RT-PCR Quick Master Mix (Toyoba Co., Ltd., Dalian, China) according to the manufacturer's protocol. qPCR was performed using LightCycler480 SYBR Green I Master (Roche Diagnostics, Indianapolis, IN, USA) at $94^{\circ} \mathrm{C}$ for $45 \mathrm{sec}$, followed by 40 cycles of $95^{\circ} \mathrm{C}$ for $30 \mathrm{sec}, 60^{\circ} \mathrm{C}$ for $45 \mathrm{sec}$ and $72^{\circ} \mathrm{C}$ for $30 \mathrm{sec}$, and then $4^{\circ} \mathrm{C}$ for $10 \mathrm{~min}$. The primer sequences are listed in Table I. Samples were quantified using the $2^{-\Delta \Delta \mathrm{Cq}}$ method (18).

Enzyme-linked immunosorbent assay of alkaline phosphatase (ALP) and triglyceride (TG). Following the treatment of BMSCs with genistein or GW9662, the activity of ALP and TG in cells was detected using an ALP and TG determination kit (Beyotime Institute of Biotechnology, Haimen, China) according to the manufacturer's protocol. The optical density was read using a microplate reader (LabSystems Miltiskan MS Plate Reader; Thermo Fisher Scientific, Inc.) at $405 \mathrm{~nm}$.

Western blotting for PPAR $\gamma$. Following the application of genistein or GW9662 to BMSCs, equal quantities of protein were analyzed using a BCA protein assay kit (Beyotime Institute of Biotechnology), according to the manufacturer's instructions. Protein was separated using $10 \%$ sodium dodecyl sulfate polyacrylamide (Sinopharm Chemical Reagent Co., Ltd.) gel electrophoresis (110 V; $45 \mathrm{~min}$ ) and transferred to polyvinylidene difluoride membranes (EMD Millipore, Billerica, MA, USA). The membrane was blocked in 5\% nonfat milk-PBS-Tween 20 solution (Shanghai Macklin Biochemical Co.,Ltd.) for $1 \mathrm{~h}$ atroom temperature, followed by separate incubation with polyclonal antibodies specific for PPAR (dilution, 1:1,000; goat anti-mouse; sc-1985; Santa Cruz Biotechnology, Inc., Dallas, TX, USA) and $\beta$-actin (dilution, 1:2,000; goat anti-mouse; sc-1616; Santa Cruz) at $4^{\circ} \mathrm{C}$ overnight. The membranes were incubated for $1 \mathrm{~h}$ at room temperature with horseradish peroxidase-conjugated secondary antibody (goat anti-mouse IgG; dilution, 1:5,000; sc-45101; Santa Cruz) in 5\% nonfat milk-PBS-Tween 20. The membranes were visualized using enhanced chemiluminescence (Thermo Fisher Scientific, Inc.), and analyzed using a Gel-Doc 2000 imaging scanner (Bio-Rad Laboratories, Inc.).

Statistical analysis. All data are expressed as the mean \pm standard error. Statistical analysis of data was performed using one-way analysis of variance and the statistical software package SPSS version 17.0 (SPSS, Inc., Chicago, IL, USA). P $<0.05$ was considered to indicate a statistically significant difference. 
Table I. Design of primer sequences.

\begin{tabular}{lll}
\hline Gene & \multicolumn{1}{c}{ Forward primer sequence } & \multicolumn{1}{c}{ Reverse primer sequence } \\
\hline Runx2 & 5'-CAGTTCCTAACGGGCACCAT-3' & 5'-TTAGGGTCTCGGAGGGAAGG-3' \\
Col I & 5'-TGACCTCAAGATGTGCCACT-3' & 5'-GGGAGTTTCCATGAAGCCAC-3' \\
OC & 5'-CATGAGAGCCCTCACA-3' & 5'-AGAGCGACACCCTAGAC-3 \\
\hline
\end{tabular}

Runx2, runt-related transcription factor 2; Col I, type I collagen; OC, osteocalcin.
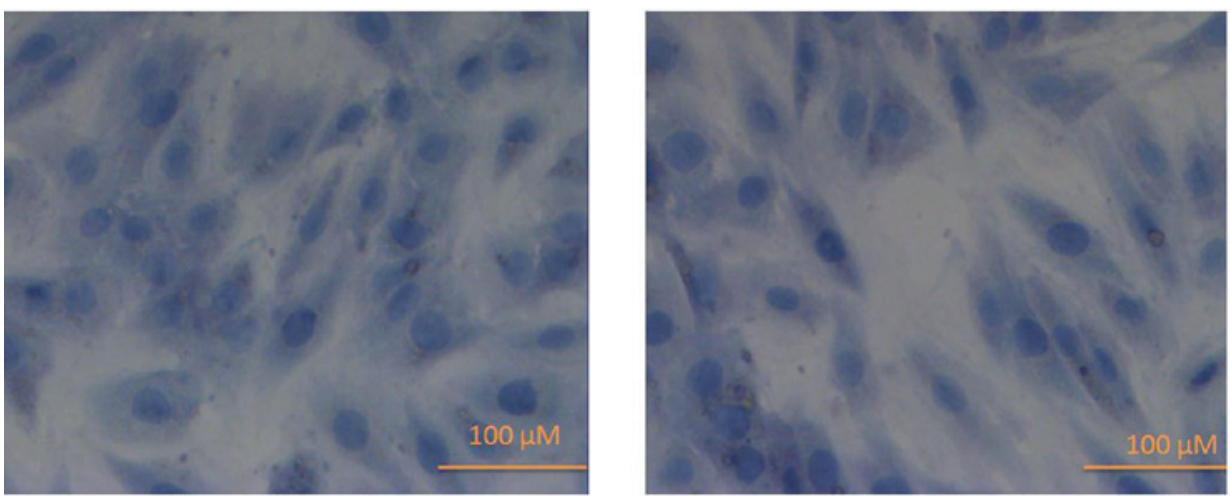

Figure 2. Authentication of bone marrow mesenchymal stem cells. The two panels are alkaline phosphatase stains of the same cell.

\section{Results}

Authenticating of BMSCs. The chemical structure of genistein is presented in Fig. 1. Fig. 2 demonstrates that the morphology of cultured BMSCs are spindle-shaped with serial subcultivation, homogeneity and multiplicity. The cell nucleus of stained BMSCs appeared dark blue (Fig. 2).

Effect of genistein on cell proliferation in BMSCs. Analysis indicated that genistein increased BMSC cell proliferation in a time- and dose-dependent manner (Fig. 3). When cells were treated with $20 \mu \mathrm{m}$ genistein for 2 and 3 days, and $10 \mu \mathrm{m}$ genistein for 3 days, BMSC cell proliferation was significantly increased compared with untreated BMSC cells $(\mathrm{P}<0.01$; Fig. 3).

Effect of genistein on Runx2, Col I and OC mRNA expression in BMSCs. As presented in Fig. 4, the expression of Runx2, Col I and OC mRNA were significantly reduced following treatment with genistein. In BMSCs, the expression of Runx 2 mRNA was significantly inhibited following treatment with $20 \mu \mathrm{m}$ genistein for 2 days, the expression of Col I mRNA was significantly reduced following treatment with 5,10 and $20 \mu \mathrm{m}$ genistein for 2 days, and the expression of OC mRNA was significantly reduced following treatment with 10 and $20 \mu \mathrm{m}$ genistein for 2 days $(\mathrm{P}<0.01$; Fig. 4).

Effect of genistein on ALP and TG activity in BMSCs. Compared with BMSCs in the absence of genistein, the activity of ALP was significantly inhibited and the activity of TG was significantly enhanced following treatment with $20 \mu \mathrm{m}$ genistein $(\mathrm{P}<0.01$; Fig. 5).
Effect of genistein on PPAR protein expression in BMSCs. To observe the mechanism of genistein on BMSCs, the protein expression of PPAR $\gamma$ was analyzed using western blotting. The results demonstrated that the protein expression of PPAR $\gamma$ was significantly increased following BMSC pretreatment with $20 \mu \mathrm{m}$ genistein for 2 days $(\mathrm{P}<0.01$; Fig. 6$)$.

Effect of PPAR $\gamma$ downregulation on genistein-induced BMSC cell proliferation. GW9662 significantly inhibited PPAR $\gamma$ protein expression in BMSCs treated with $20 \mu \mathrm{m}$ genistein for 2 days, compared with BMSCs treated only with $20 \mu \mathrm{m}$ genistein $(\mathrm{P}<0.01$; Fig. 7A and $\mathrm{B})$. In addition, GW9662 significantly reduced the effect of $20 \mu \mathrm{m}$ genistein on BMSC cell proliferation compared with cells treated only with $20 \mu \mathrm{m}$ genistein $(\mathrm{P}<0.01$; Fig. 7C).

Effect of PPAR $\gamma$ downregulation on Runx2, Col I and OC mRNA expression and the activity of ALP and TG in BMSCs. As presented in Fig. 8A, the effect of $20 \mu \mathrm{m}$ genistein on the expression of Runx2, Col I and OC mRNAs was significantly reduced following pretreatment with a PPAR $\gamma$ inhibitor for 2 days $(\mathrm{P}<0.01)$, compared with cells treated only with $20 \mu \mathrm{m}$ genistein for 2 days. In addition, the genistein-induced increase in TG activity and reduction in ALP activity were significantly inhibited by a PPAR $\gamma$ inhibitor $(\mathrm{P}<0.01$; Fig. $8 \mathrm{~B}$ and $\mathrm{C})$.

\section{Discussion}

A number of local factors and hormones are required to transmit signals to transcription factors when BMSCs differentiate in osteogenesis, and these control the expression of specific genes during each stage of BMSC differentiation, thus controlling the 


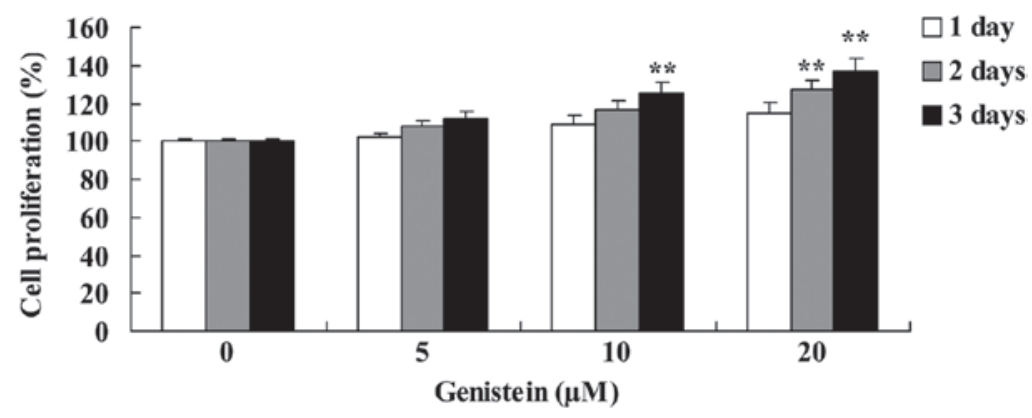

Figure 3. Genistein promotes cell proliferation of bone marrow mesenchymal stem cells. ${ }^{* *} \mathrm{P}<0.01$ vs. the $0 \mu \mathrm{M}$ genistein group.

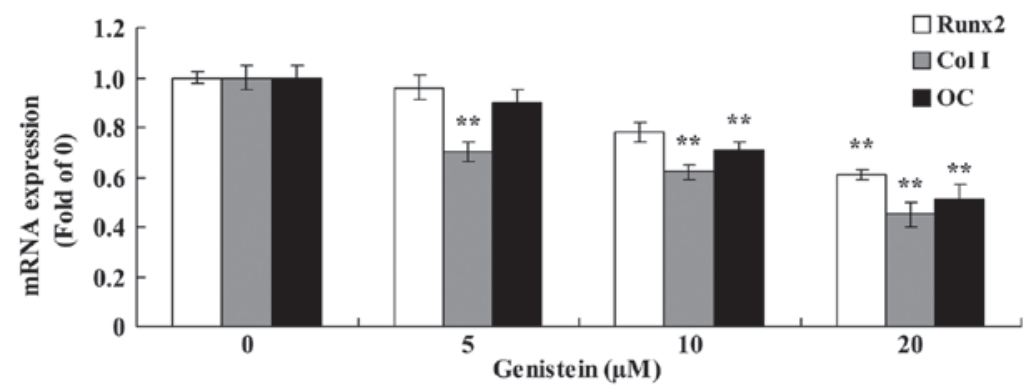

Figure 4. Effect of genistein on Runx2, Col I and OC mRNAs expression of bone marrow mesenchymal stem cells. ${ }^{* *} \mathrm{P}<0.01$ vs. the $0 \mu \mathrm{M}$ genistein group. Runx2, runt-related transcription factor 2; Col I, type I collagen; OC, osteocalcin.

A

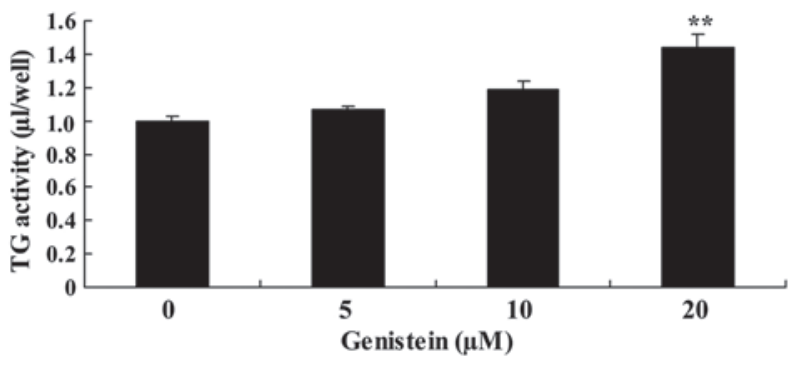

B

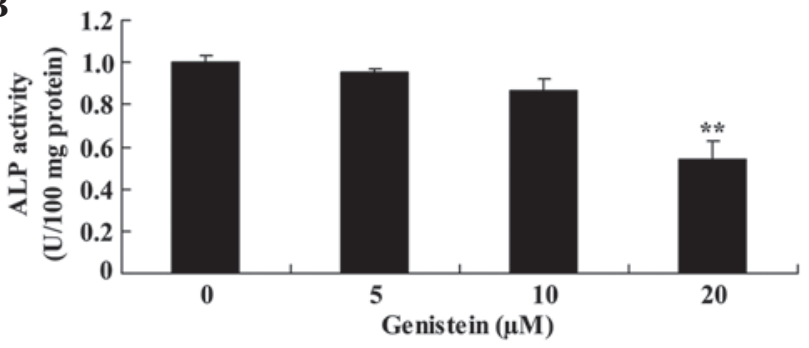

Figure 5. Effect of genistein on (A) TG and (B) ALP activities in bone marrow mesenchymal stem cells. ${ }^{* *} \mathrm{P}<0.01 \mathrm{vs}$. the $0 \mu \mathrm{M}$ genistein group. TG, triglyceride; ALP, alkaline phosphatase.

A

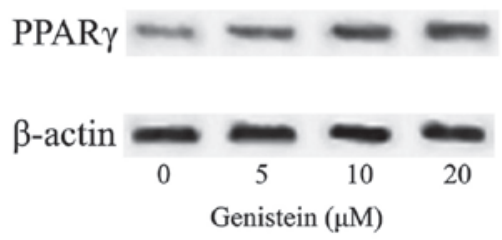

B

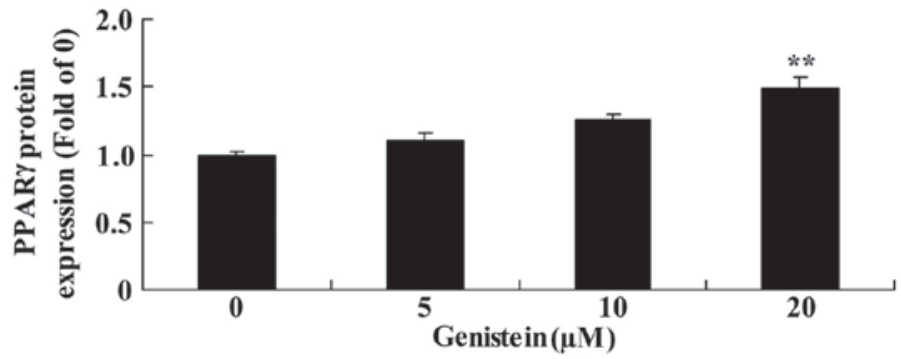

Figure 6. Effect of genistein on PPAR $\gamma$ protein expression in BMSCs. (A) Western blot analysis of the effect of genistein on PPAR $\gamma$ protein expression and (B) statistical analysis of PPAR $\gamma$ protein expression in BMSCs. ${ }^{* *} \mathrm{P}<0.01$ vs. the $0 \mu \mathrm{M}$ genistein group. PPAR $\gamma$, peroxisome proliferator-activated receptor $\gamma$; BMSCs, bone marrow mesenchymal cells.

osteoblast at each stage $(1,2)$. Once mesenchymal stem cells become osteoblasts, the osteogenic cells proliferate as a result of mitotic growth factors, which ensure that a sufficient quantity of osteoblasts are generated for osteogenesis (19). Meanwhile, osteogenic cells undergo differentiation into mature osteoblasts during osteogenesis (20).
OC, ALP, Runx 2 and $\mathrm{Col} I$ are derived during the synthesis of osteoblasts. At different stages of osteogenesis, only part of the aforementioned proteins and factors may be generated (21). With the generation of OC, Runx 2 and Col I, osteoblasts will enter into different stages of differentiation (22). Thus, the synthesis and secretion of such proteins are significant markers 
A

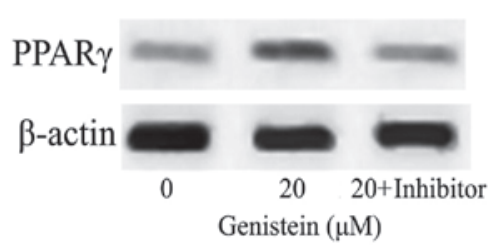

B

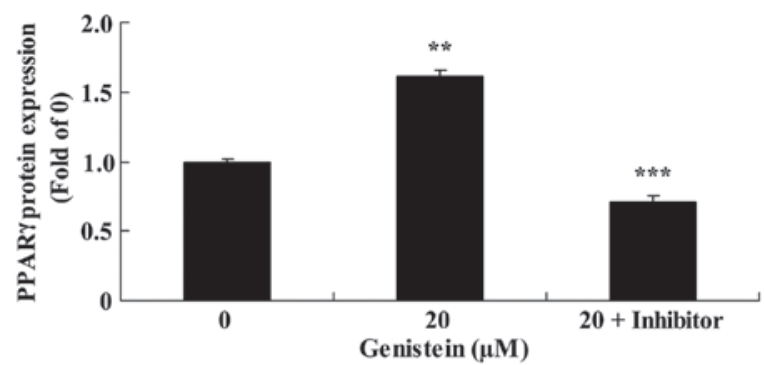

C

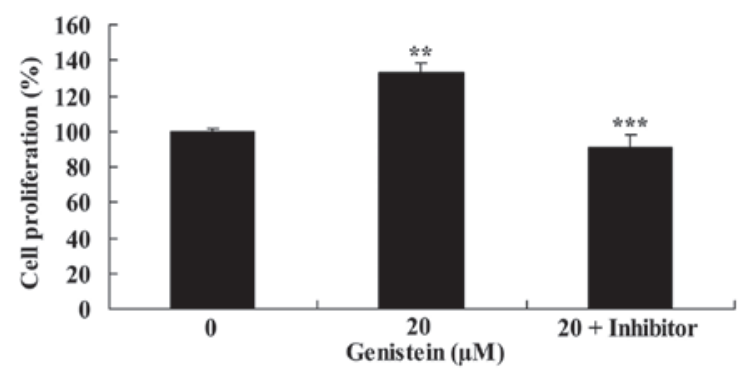

Figure 7. Effects of PPAR $\gamma$ downregulation on genistein-induced cell proliferation of BMSCs. (A) Western blot analysis to analyze the effect of genistein on PPAR $\gamma$ protein expression, (B) statistical analysis of PPAR $\gamma$ protein expression and $(\mathrm{C})$ the effect of genistein on cell proliferation of BMSCs. ${ }^{* *} \mathrm{P}<0.01$ vs. $0 \mu \mathrm{M}$ genistein group; ${ }^{* * *} \mathrm{P}<0.01$ vs. $20 \mu \mathrm{M}$ genistein group. PPAR $\gamma$, peroxisome proliferator-activated receptor $\gamma$; BMSCs, bone marrow mesenchymal cells.

of osteoblast differentiation, and affect the biological function and performance of osteoblasts (23).

In the present study, genistein significantly accelerated BMSC cell proliferation, reduced Runx 2 , Col I and OC mRNA expression, and inhibited the activity of ALP and increased the activity of TG, which suggests that genistein has the potential to be used as a BMSC inductive agent. In particular, Relic et al (24) reported that genistein induces adipogenesis through activating PPAR $\gamma$ pathway.

BMSCs possess a multipotent differentiation potential that allows them to differentiate into a variety of cell osteoblasts, including chondrocytes, adipocytes and myoblasts, by a number of induction pathways, and this directional differentiation can alter when the differentiation induction system changes (25). When osteogenesis- and chondrogenesis-inducing factors are present in BMSC culture systems, the expression of PPAR $\gamma$ is significantly increased and an increased number of adipocytes are generated (3). Osteoblasts are able to generate a variety of cytokines that regulate the differentiation and apoptosis of osteoclasts in various stages of differentiation proliferation, maturation and mineralization (26). Therefore, the effect of the PPAR $\gamma$ gene and its ligand on osteoblasts may alter the levels of cytokines in the bone marrow microenvironment, resulting in a direct or indirect influence on the differentiation and function of osteoclasts $(3,8)$.
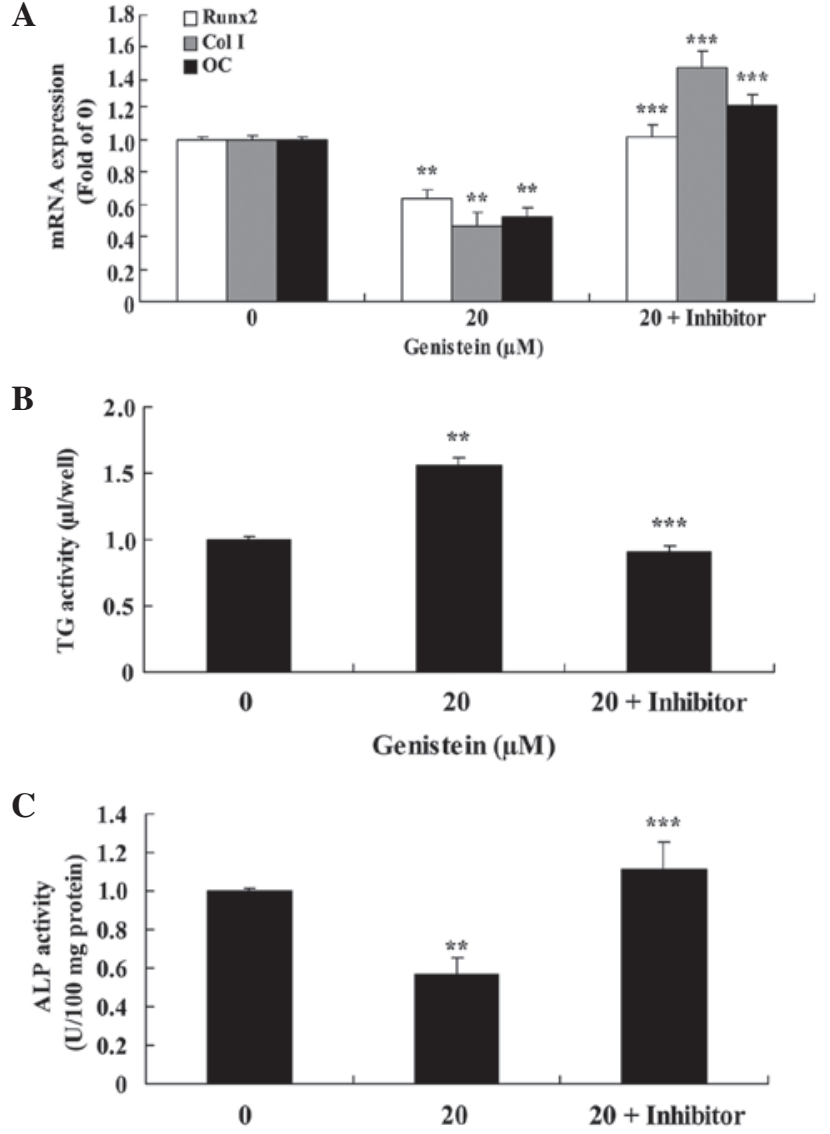

Figure 8. Effect of PPAR $\gamma$ downregulation on (A) Runx2, Col I and OC mRNA expression and (B) TG and (C) ALP activity in bone marrow mesenchymal stem cells. ${ }^{* *} \mathrm{P}<0.01$ vs. the $0 \mu \mathrm{M}$ genistein group; ${ }^{* * *} \mathrm{P}<0.01 \mathrm{vs.} 20 \mu \mathrm{M}$ genistein group. PPAR $\gamma$, peroxisome proliferator-activated receptor $\gamma$; Runx2, runt-related transcription factor 2; Col I, type I collagen; OC, osteocalcin; TG, triglyceride; ALP, alkaline phosphatase.

Results from the present study demonstrated that BMSC pretreatment with $20 \mu \mathrm{m}$ genistein significantly activates PPAR $\gamma$ protein expression. Similarly, a previous report observed that genistein inhibits human osteosarcoma MG-63 cells by activating the PPAR $\gamma$ signaling pathway (27). In addition, Chatterjee et al (28) demonstrated that genistein prevents Alzheimer's disease-associated inflammation through increasing PPAR $\gamma$ expression in cultured astrocytes (29).

PPAR was identified as a substance that may be activated by a peroxysome proliferation stimulator of a fatty acid-like compound (30). It was observed in vitro and in vivo that PPAR served an important role in the regulation of BMSC differentiation (31). A number of studies report that the PPAR $\gamma$ genes possesses an influence on the pathogenesis of osteoporosis induced by microgravity; under simulated microgravity conditions, the expression of PPAR $\gamma$ is increased, thus enhancing the activity of PPAR $\gamma$, as well as its target gene adipsin and recombinant human leptin $(32,33)$. The present study observed that downregulation of PPAR $\gamma$ reduced the effect of genistein-induced BMSC cell growth, inhibited genistein-induced adipogenic differentiation and suppressed the osteogenic potential of BMSCs.

In conclusion, the results from the current study demonstrate that genistein promotes cell growth, induces adipogenic differentiation and suppresses the osteogenic potential of BMSCs by 
upregulating PPAR $\gamma$ expression. To conclude, genistein may be a potential therapeutic agent for the treatment of orthopedic diseases.

\section{Acknowledgements}

The current study was supported by the National Natural Science Foundation of China subsidization project (no. 81301564), the Army Medical Science Youth Training Project (no. 13QNP184), the 'Twelfth Five-Year Plan' Science and Technology Research Project of Jilin Province Department of Education (no. 141) and the Jilin Province Science and Technology Department Project (no. 20130624003JC).

\section{References}

1. Katsuda T, Tsuchiya R, Kosaka N, Yoshioka Y, Takagaki K, Oki K, Takeshita F, Sakai Y, Kuroda M and Ochiya T: Human adipose tissue-derived mesenchymal stem cells secrete functional neprilysin-bound exosomes. Sci Rep 3: 1197, 2013.

2. Dumont N, Boyer L, Émond H, Celebi-Saltik B, Pasha R, Bazin R, Mantovani D, Roy DC and Pineault N: Medium conditioned with mesenchymal stromal cell-derived osteoblasts improves the expansion and engraftment properties of cord blood progenitors. Exp Hematol 42: 741-752.e1, 2014.

3. Kawai M, Green CB, Lecka-Czernik B, Douris N, Gilbert MR, Kojima S, Ackert-Bicknell C, Garg N, Horowitz MC, Adamo ML, et al: A circadian-regulated gene, Nocturnin, promotes adipogenesis by stimulating PPAR-gamma nuclear translocation. Proc Natl Acad Sci USA 107: 10508-10513, 2010

4. Lv FH, Gao JZ, Teng QL and Zhang JY: Effect of folic acid and vitamin B12 on the expression of PPAR $\gamma$, caspase- 3 and caspase- 8 mRNA in the abdominal aortas of rats with hyperlipidemia. Exp Ther Med 6: 184-188, 2013.

5. Zhou Y, Zhu ZL, Guan XX, Hou WW and Yu HY: Reciprocal roles between caffeine and estrogen on bone via differently regulating cAMP-PKA pathway: The possible mechanism for caffeine-induced osteoporosis in women and estrogen's antagonistic effects. Med Hypotheses 73: 83-85, 2009.

6. Lu T, Huang Y, Wang H, Ma Y and Guan W: Multi-lineage potential research of bone marrow-derived stromal cells (BMSCs) from cattle. Appl Biochem Biotechnol 172: 21-35, 2014.

7. Fan J, Li J and Fan Q: Naringin promotes differentiation of bone marrow stem cells into osteoblasts by upregulating the expression levels of microRNA-20a and downregulating the expression levels of PPARgamma. Mol Med Rep 12: 4759-4765, 2015.

8. Weivoda MM and Hohl RJ: Geranylgeranyl pyrophosphate stimulates PPAR $\gamma$ expression and adipogenesis through the inhibition of osteoblast differentiation. Bone 50: 467-476, 2012

9. Cao J, Ou G, Yang N, Ding K, Kream BE, Hamrick MW, Isales CM and Shi XM: Impact of targeted PPAR $\gamma$ disruption on bone remodeling. Mol Cell Endocrinol 410: 27-34, 2015.

10. Chen Y, Chen L, Yin Q, Gao H, Dong P, Zhang X and Kang J: Reciprocal interferences of TNF- $\alpha$ and Wnt1- $\beta$-catenin signaling axes shift bone marrow-derived stem cells towards osteoblast lineage after ethanol exposure. Cell Physiol Biochem 32: 755-765, 2013

11. Hirayama K, Matsuzuka Y, Kamiya T, Ikeguchi M, Takagaki $\mathrm{K}$ and Itoh K: Metabolism of isoflavones found in the Pueraria thomsonii flower by human intestinal microbiota. Biosci Microflora 30: 135-140, 2011.

12. Kim SH, Kim CW, Jeon SY, Go RE, Hwang KA and Choi KC: Chemopreventive and chemotherapeutic effects of genistein, a soy isoflavone, upon cancer development and progression in preclinical animal models. Lab Anim Res 30: 143-150, 2014.

13. Nagaraju GP, Zafar SF and El-Rayes BF: Pleiotropic effects of genistein in metabolic, inflammatory, and malignant diseases. Nutr Rev 71: 562-572, 2013.

14. Menze ET, Esmat A, Tadros MG, Abdel-Naim AB and Khalifa AE: Genistein improves 3-NPA-induced memory impairment in ovariectomized rats: Impact of its antioxidant, anti-inflammatory and acetylcholinesterase modulatory properties. PLoS One 10: e0117223, 2015.
15. Chen J, Duan Y, Zhang X, Ye Y, Ge B and Chen J: Genistein induces apoptosis by the inactivation of the IGF-1R-p-Akt signaling pathway in MCF-7 human breast cancer cells. Food Funct 6: 995-1000, 2015.

16. Liao MH, Tai YT, Cherng YG, Liu SH, Chang YA, Lin PI and Chen RM: Genistein induces oestrogen receptor- $\alpha$ gene expression in osteoblasts through the activation of mitogen-activated protein kinases-NF- $\kappa \mathrm{B}$-activator protein-1 and promotes cell mineralisation. Br J Nutr 111: 55-63, 2014.

17. Zeng X, Yu SP, Taylor T, Ogle M and Wei L: Protective effect of apelin on cultured rat bone marrow mesenchymal stem cells against apoptosis. Stem Cell Res (Amst) 8: 357-367, 2012.

18. Livak KJ and Schmittgen TD: Analysis of relative gene expression data using real-time quantitative PCR and the $2^{-\Delta \Delta C}$ method. Methods 25: 402-408, 2001

19. Pauksch L, Hartmann S, Szalay G, Alt V and Lips KS: In vitro assessment of nanosilver-functionalized PMMA bone cement on primary human mesenchymal stem cells and osteoblasts. PLoS One 9: e114740, 2014.

20. Lee S, Cho HY, Bui HT and Kang D: The osteogenic or adipogenic lineage commitment of human mesenchymal stem cells is determined by protein kinase $\mathrm{C}$ delta. BMC Cell Biol 15: 42, 2014

21. Antoniou J, Wang HT, Alaseem AM, Haglund L, Roughley PJ and Mwale F: The effect of Link N on differentiation of human bone marrow-derived mesenchymal stem cells. Arthritis Res Ther 14: R267, 2012.

22. Nichols RA Jr, Niagro FD, Borke JL and Cuenin MF: Mechanical stretching of mouse calvarial osteoblasts in vitro models changes in MMP-2 and MMP-9 expression at the bone-implant interface. J Oral Implantol: May 11, 2015 (Epub ahead of print).

23. Hu HM, Yang L, Wang Z, Liu YW, Fan JZ, Fan J, Liu J and Luo ZJ: Overexpression of integrin $\alpha 2$ promotes osteogenic differentiation of hBMSCs from senile osteoporosis through the ERK pathway. Int J Clin Exp Pathol 6: 841-852, 2013.

24. Relic B, Zeddou M, Desoroux A, Beguin Y, de Seny D and Malaise MG: Genistein induces adipogenesis but inhibits leptin induction in human synovial fibroblasts. Lab Invest 89: 811-822, 2009.

25. Arrigoni C, De Luca P, Gilardi M, Previdi S, Broggini M and Moretti M: Direct but not indirect co-culture with osteogenically differentiated human bone marrow stromal cells increases RANKL-OPG ratio in human breast cancer cells generating bone metastases. Mol Cancer 13: 238, 2014.

26. Choudhary S, Goetjen A, Estus T, Jacome-Galarza CE, Aguila HL, Lorenzo J and Pilbeam C: Serum amyloid A3 secreted by preosteoclasts inhibits parathyroid hormone-stimulated cAMP signaling in murine osteoblasts. J Biol Chem: 23 Dec, 2015 (Epub ahead of print). pii jbc.M115.686576.

27. Song M, Tian X, Lu M, Zhang X, Ma K, Lv Z, Wang Z, Hu Y, Xun C, Zhang Z and Wang S: Genistein exerts growth inhibition on human osteosarcoma MG-63 cells via PPAR $\gamma$ pathway. Int J Oncol 46: 1131-1140, 2015.

28. Chatterjee G, Roy D, Khemka VK, Chattopadhyay M and Chakrabarti S: Genistein, the isoflavone in soybean, causes amyloid beta peptide accumulation in human neuroblastoma cell line: Implications in Alzheimer's disease. Aging Dis 6: 456-465, 2015

29. Valles SL, Dolz-Gaiton P, Gambini J, Borras C, Lloret A, Pallardo FV and Viña $\mathrm{J}$ : Estradiol or genistein prevent Alzheimer's disease-associated inflammation correlating with an increase PPAR gamma expression in cultured astrocytes. Brain Res 1312: 138-144, 2010.

30. Zhuang H, Zhang X, Zhu C, Tang X, Yu F, Shang GW and Cai X: Molecular mechanisms of PPAR $\gamma$ governing MSC osteogenic and adipogenic differentiation. Curr Stem Cell Res Ther: 31 May, 2015 (Epub ahead of print).

31. Zhou H, Yang X, Wang N, Zhang Y and Cai G: Tigogenin inhibits adipocytic differentiation and induces osteoblastic differentiation in mouse bone marrow stromal cells. Mol Cell Endocrinol 270: 17-22, 2007

32. Wang L, Li L, Gao H and Li Y: Effect of pioglitazone on transdifferentiation of preosteoblasts from rat bone mesenchymal stem cells into adipocytes. J Huazhong Univ Sci Technolog Med Sci 32: 530-533, 2012.

33. Lee NJ, Doyle KL, Sainsbury A, Enriquez RF, Hort YJ, Riepler SJ, Baldock PA and Herzog H: Critical role for Y1 receptors in mesenchymal progenitor cell differentiation and osteoblast activity. J Bone Miner Res 25: 1736-1747, 2010. 